Bài báo khoa học

\title{
Xây dựng bộ tiêu chí đánh giá các hệ thống nuôi trồng thuỷ sản ven biển thông minh thích ứng với biến đổi khí hậu cho vùng ven biển Bắc Bộ-Bắc Trung $B$ ọ
}

\author{
Hoàng Ngọc Khắc ${ }^{1,2^{*}}$, Trịnh Quang Túa ${ }^{3}$ Trần Văn $\operatorname{Tam}^{3}$ \\ 1 Viện Nghiên cứu Biến đổi toàn cầu và Phát triển bền vững; hnkhac@hunre.edu.vn; \\ 2 Trường Đại học Tài nguyên và Môi trường Hà Nội; \\ 3 Viện Kinh tế và Quy hoạch Thủy Sản; tiquatuwagen@gmail.com; hanhtam.vifep@gmail.com. \\ * Tác giả liên hệ: hnkhac@hunre.edu.vn; Tel.: +84-987.8220723
}

Ban Biên tập nhận bài: 15/6/2020; Ngày phản biện xong: 13/8/2020; Ngày đăng bài: 25/8/2020

Tóm tắt: Nuôi trồng thủy sản (NTTS) thông minh thích ứng với Biến đổi khí hậu (Climate Smart Aquaculture), được đề xuất bởi Tổ chức Nông nghiệp và Lương thực Liên Hợp QuốcFAO (2010) trong khuôn khổ tiếp cận nông nghiệp thông minh thích ứng với Biến đổi khí hậu (CSA), là hướng tiếp cận tổng hợp thúc đây sự cải tiến, chuyển đổi trong lĩnh vực NTTS ở tất cả các cấp độ (trang trại, địa phương, vùng quốc gia) nhằm giải quyết những thách thức và nâng cao tính thích ứng của các hệ thống NTTS trước tác động gia tăng của BĐKH. Việc áp dụng các mô hình NTTS thông minh thích ứng với BĐKH tại Việt Nam, hiện đang được áp dụng và nhân rộng, đặc biệt là tại các tỉnh, thành phố ven biển vùng Bắc Bộ-Bắc Trung Bộ. Đê đánh giá các hệ thông NTTS thông minh thích ứng với $\mathrm{B} Đ K H$, Bộ tiêu chí đánh giá được xây dựng, trên cơ sở ba nhóm trụ cột chính trong tiếp cận CSA, bao gồm nhóm tiêu chí về đảm bảo an ninh lương thực (ANLT), nhóm tiêu chí thích ứng và phục hồi với $\mathrm{B} Đ K H$, và nhóm tiêu chí về giảm phát thải khí nhà kính $(\mathrm{KNK})$. Bộ tiêu chí được áp dụng có ý nghĩa thiết thực trong việc đánh giá tính hiệu quả và cải thiện các hệ thống NTTS thông minh thích ứng với $\mathrm{B} Đ K H$ cho vùng Bắc Bộ-Bắc Trung Bộ cũng như mở rộng cho các tỉnh thành ven biển Việt Nam.

Từ khóa: An ninh lương thực; Bộ tiêu chí; Khí nhà kính; NTTS thông minh.

\section{1. Đặt vấn đề}

Trong khái niệm của tổ chức nông lương thế giới [1], nông nghiệp trong CSA được hiểu là bao gồm cả trồng trọt, chăn nuôi, thủy sản và lâm nghiệp. Theo [1] CSA là một cách tiếp cận nhằm xác định các hệ thống sản xuất và cơ chế quản lý phù hợp nhất để thích ứng được với các thay đổi của khí hậu tại một địa điểm cụ thể. Theo các tiêu chí về CSA được định nghĩa bởi [2] thì các giải pháp ứng phó trong nuôi trồng thủy sản ven biển để triển khai các thực hành nuôi trồng thủy sản thông minh với $\mathrm{BĐKH} \mathrm{bao} \mathrm{gồm} \mathrm{như} \mathrm{sau:} \mathrm{(1)} \mathrm{Cải} \mathrm{thiện} \mathrm{việc} \mathrm{sử} \mathrm{dụng} \mathrm{yếu} \mathrm{tố} \mathrm{đầu}$ vào cho sản xuất: Tối ưu hoá các yếu tố đầu vào hướng tới việc sử dụng có hiệu quả các nguyên liệu đầu vào thông qua các biện pháp kỹ thuật để giảm chi phí sản xuất, giảm ô nhiễm môi trường và giảm phát thải $\mathrm{KNK}$. Đồng thời, khai thác sử dụng bền vững nguồn nước: áp dụng các biện pháp/kỹ thuật nuôi ít thay nước, tuần hoàn nước, xử lý nước thải từ ao nuôi...; (2) Đa dạng hóa và thay đổi cơ cấu con giống nuôi trồng để thích ứng với $\mathrm{BĐKH:} \mathrm{thực} \mathrm{hiện} \mathrm{các} \mathrm{thực} \mathrm{hành}$ 
nuôi trồng thủy sản luân canh, xen canh để tận dụng cơ sở thức ăn tự nhiên, thân thiện với môi trường, hoặc nghiên cứu các giống mới có đặc điểm chống chịu tốt hơn với $\mathrm{BĐKH;} \mathrm{(3)} \mathrm{Tiếp} \mathrm{cận}$ thị trường: kết nối với doanh nghiệp để đầy mạnh tiêu thụ, quảng bá các sản phẩm nuôi trồng thân thiện với môi trường, các sản phẩm nuôi trồng có trách nhiệm và giúp giảm thiểu $\mathrm{BĐKH} \mathrm{để}$ nhân rộng các giải pháp và thực hành về CSA.

Nhận thức được vai trò của NTTS như một ngành sản xuất lương thực quan trọng và trên cơ sở tiếp cận CSA, FAO [1] đã khuyến nghị ba nhóm thực hành và các hoạt động cụ thể trong việc xây dựng các chiến lược CSA khác nhau cho ngành NTTS: (i) Tăng sản lượng/năng suất và hiệu quả một cách bền vững, khởi đầu tập trung vào việc tăng mức độ thâm canh, áp dụng tốt hơn các hệ thống canh tác kết hợp, cải thiện chất lượng nguồn giống, nâng cao hiệu quả sử dụng thức ăn và giảm thiệt hại do dịch bệnh; (ii) Giảm tính tổn thương và tăng khả năng phục hồi đối với các hệ thống NTTS như: cải tiến việc lựa chọn và thiết kế các trang trại NTTS; áp dụng hình thức bảo hiểm theo trang trại/nhóm trang trại; sử dụng các loài nuôi bản địa hoặc đơn tính (không thể sinh sản) để giảm thiểu các tác động đển đa dạng sinh học, nâng cao hiệu quả sử dụng tài nguyên nước, chuyển từ hoạt động khai thác sang NTTS ven biển, lựa chọn các đối tượng nuôi ngắn ngày, nâng cao hiệu quả sử dụng nước và hoặc chia sẻ nguồn nước, cải thiện chất lượng và hiệu quả của các giống NTTS; và (iii) Giảm thiểu và loại bỏ KNK. Đối với nhóm thực hành này, các giải pháp trước mắt là áp dụng hệ thống NTTS đa tầng kết hợp (nuôi kết hợp nhiều đối tượng với các tầng thức ăn khác nhau) và cải thiện/nâng cao hoạt động quản lý trại/ao NTTS.

Tác động của $\mathrm{BĐKH}$ và các tổn thất liên quan là không thể tránh khỏi trong vài thập kỷ tới trong bối cảnh gia tăng $\mathrm{BĐKH}$ và nước biển dâng ngay cả với những nỗ lực giảm thiểu tối đa [3]. Điều này chỉ ra rằng thích ứng với $\mathrm{B} Đ K H$ mang tính cấp thiết và bắt buộc. Các giải pháp thích ứng phù hợp có thể làm giảm thiểu đáng kể thiệt hại do tác động của $\mathrm{B} Đ K H$, trong khi các giải pháp thích ứng không hiệu quả có thể làm gia tăng chi phí [4]. Tuy nhiên, bằng cách sử dụng kết quả nghiên cứu như một chỉ số, [5] cho thấy rằng, trong gần một thập kỷ, nghiên cứu về thích ứng $\mathrm{BĐKH} \mathrm{ít} \mathrm{được} \mathrm{quan} \mathrm{tâm} \mathrm{so} \mathrm{với} \mathrm{các} \mathrm{đánh} \mathrm{giá} \mathrm{tác} \mathrm{động} \mathrm{BĐKH.} \mathrm{Gần} \mathrm{đây,} \mathrm{nghiên} \mathrm{cứu} \mathrm{về} \mathrm{thích}$ ứng $\mathrm{BĐKH}$ có chiều hướng gia tăng, trong đó một số nghiên cứu đã có sự phân tích về vấn đề chi phí và lợi ích của các giải pháp thích ứng $\mathrm{BĐKH} \mathrm{[6].}$

Nhằm đưa ra phương pháp cho lựa chọn các thực hành CSA trong bối cảnh nguồn lực hạn chế, đặc biệt đối với các quốc gia đang và kém phát triển, năm 2015, CIAT và CCAFS [7] đưa ra khung phân tích CSA-PF, trong đó, khung phân tích đề xuất phương pháp: (i) xác định các hệ thống canh tác nông nghiệp, chăn nuôi và các vùng trọng yếu (dễ bị tổn thương) cho vấn đề NBLT quốc gia/vùng; (ii) xác định các lựa chọn CSA hiện có và có tiềm năng (thực hành, công nghệ, dịch vụ) liên quan đến các hệ thống sản xuất và các vùng trọng điểml (iii) đánh giá các kết quả cụ thể của các thực hành về năng xuất/ ANLT, các chỉ số thích ứng/khả năng phục hội và giảm phát thải; (iv) phân tích chi phí-lợi ích của việc triển khai thực hành CSA, cũng như các cơ hội và rào cản đói với việc áp dụng các thực hành $C S A$; và (v) xác định các chiến lượng và chính sach có trong hỗ trợ triển khai, và/ hoặc nhân rộng áp dụng các thực hành CSA (ví dụ như các chương trình bảo hiểm và tín dụng, các hệ thống cảnh báo sớm...).

Các chiến lược về thích ứng và giảm thiểu thông minh với $\mathrm{BĐKH} \mathrm{được} \mathrm{giới} \mathrm{thiệu} \mathrm{ở} \mathrm{Nigeria}$ giúp tăng khả năng phục hồi và thích ứng của cộng đồng và các hệ sinh thái [8]. Nghiên cứu cũng chỉ ra tính dễ bị tổn thương của NTTS trong bối cảnh BĐKH tác động tới tài nguyên thiên nhiên liên quan đến việc xây dựng các mô hình NTTS như nước, đất, con giống, loài, năng lượng và nguồn thức ăn. Việc xây dựng các mô hình NTTS thông minh thích ứng BĐKH do đó, được đề xuất triển khai cho Nigeria nhằm đảm bảo năng suất ngành NTTS và môi trường sinh thái. Tuy nhiên, đề tài cũng cho thấy vấn đề trong việc áp dụng các mô hình NTTS thông minh bao 
gồm chi phí áp dụng cao từ giai đoạn đầu, hạn chế trong việc tiếp cận các dịch vụ khuyến nông và thông tin và gặp khó khăn với các yếu tố văn hóa địa phương như truyền thống, quy định và các chuẩn mực. Do đó, việc áp dụng các mô hình NTTS thông minh còn cần phải được đánh giá cụ thể mức độ hiệu quả và tiềm năng thực hiện cho từng vùng khác nhau dựa trên công tác xây dựng các bộ tiêu chí đánh giá mô hình.

Như vậy, việc áp dụng các mô hình NTTS thông minh thích ứng với BĐKH còn cần phải được đánh giá và xem xét cụ thể để đạt được ba mục tiêu trụ cột của CSA. Do đó, nghiên cứu tập trung xây dựng các tiêu chí, bộ tiêu chí phù hợp với ba mục tiêu để đánh giá khả năng và hiệu quả áp dụng của các mô hình NTTS cho các vùng Bắc Bộ-Bắc Trung Bộ là bước đầu để thực hiện triển khai mô hình cho các vùng ven biển Việt Nam. Các tiêu chí đánh giá cần được đề ra và tính điểm theo từng mục tiêu cho các vùng nghiên cứu dựa trên số liệu thực tế thu thập và ý kiến chuyên gia.

Vùng duyên hải Bắc Bộ và Bắc Trung Bộ (BB$\mathrm{BTB})$, bao gồm 11 tỉnh, thành phố ven biển, trải dài từ Quảng Ninh tới Thừa Thiên Huế, là khu vực phát triển chủ yếu dựa vào sản xuất nông nghiệp và thủy sản (Hình 1). Đây cũng là vùng có sự đa dạng về hệ thống canh tác, phương thức cũng như đối tượng nuôi và đóng vai trò quan trọng đến thương mại và kinh tế - xã hội ở Việt Nam. Vùng duyên hải Bắc Bộ có bãi triều rộng và phù sa dày là cơ sở nuôi trồng thuỷ hải sản, nuôi rong câu và chăn vịt ven bờ. Trong khi đó, khu vực Bắc Trung Bộ có đường bờ biển kéo dài, biển vùng này khá sâu ở sát bờ, nhiều eo biển, cửa sông, vũng, vịnh thuận lợi cho phát triển kinh tế biển du lịch, giao thông biển, đánh bắt cá, phát triển các hải cảng lớn.

Do đây là khu vực có tiềm năng phát triển NTTS lớn của cả nước, việc đánh giá khả năng ứng dụng các mô

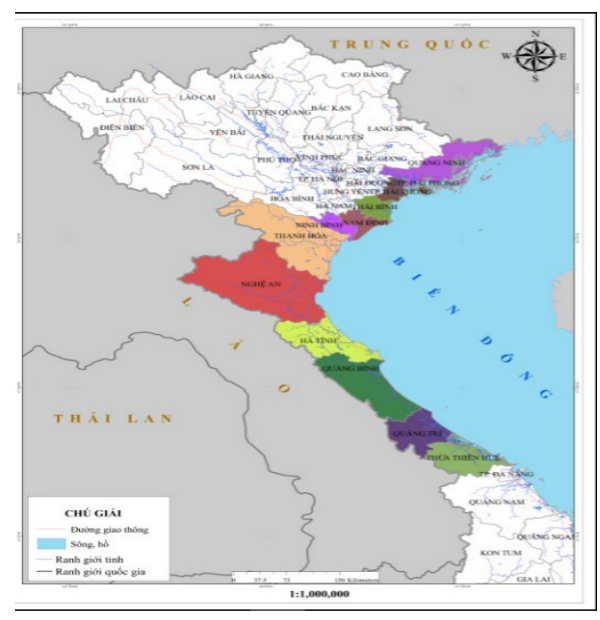

Hình 1. Các tỉnh thành ven biển vùng $B B-B T B$.

hình NTTS thông minh thích ứng BĐKH là cần thiết để tiến hành lựa chọn và triển khai các mô hình phù hợp cho từng tỉnh thành cũng như nhân rộng trên cả nước, đảm bảo các mục tiêu giảm thiểu tác động tiêu cực của $\mathrm{B} Đ K H$ và đảm bảo được an ninh lương thực quốc gia cũng như đóng góp thúc đẩy kinh tế Việt Nam trong bối cảnh của BĐKH toàn cầu.

\section{Dữ liệu và phương pháp nghiên cứu}

Từ mục tiêu xác lập bộ chỉ số đánh giá các mô hình NTTS thông minh thích ứng BĐKH khu vực Bắc Bộ-Bắc Trung Bộ, bài báo đã tiến hành điều tra trên diện rộng và chi tiết tại các vùng NTTS các yếu tố đảm bảo được ba mục tiêu trụ cột của CSA. Do đó, ngoài việc thu thập thống kê các tài liệu, tư liệu từ các kết quả nghiên cứu từ các dự án có liên quan song song với việc điều tra khảo sát thực địa tại các tỉnh, vùng, địa phương, đề tài còn tiến hành các bảng điều tra phỏng vấn và đánh giá nhanh nông thôn.

Dữ liệu thu thập từ các tỉnh thành và các khu vực NTTS được thực hiện từ các hộ NTTS, các mô hình NTTS tại địa phương qua các bảng câu hỏi và phiếu điều tra. Thông tin về điều kiện môi trường, vị trí và số hộ NTTS, số mô hình NTTS, các loại hình NTTS, sản lượng và năng suất NTTS, diện tích NTTS và các ứng dụng công nghệ được sử dụng tại các ao nuôi được thu thập nhằm đánh giá định tính và định lượng tiềm năng phát triển của mô hình. 
Công tác phỏng vấn dựa vào các phiếu điều tra với bảng câu hỏi dựa trên ba mục tiêu đánh giá trụ cột đến người dân tại khu vực nghiên cứu. Các câu hỏi với nội dung nhằm phân tích đánh giá các yếu tố kinh tế, xã hội, môi trường, tai biến cũng như khả năng thích ứng và chống chịu của hệ thống xã hội. Ngoài ra, thực hiện tham vấn cộng đồng để đóng góp, hoàn thiện và kiểm chứng lại các tiêu chí đưa ra... Đối tượng phỏng vấn được chia thành hai, bao gồm cán bộ cấp huyện, xã và người dân, bảng câu hỏi vì thế được thiết kế với các nội dung phù hợp với đối tượng được phỏng vấn. Trước đợt phỏng vấn, các điều tra viên được tập huấn, nắm rõ nội dung của phiếu và phỏng vấn trực tiếp các hộ gia đình, sau đó và tự ghi thông tin thu thập được vào phiếu.

Đồng thời, phương pháp đánh giá nhanh nông thôn có sự tham gia được sử dụng trong nghiên cứu này để thu thập các thông tin của các cộng đồng NTTS khu vực ven biển Bắc Bộ và Bắc Trung Bộ, phục vụ cho việc đánh giá, phân tích hiện trạng NTTS ven biển, làm cơ sở cho việc xây dựng tiêu chí đánh giá, kế hoạch, triển khai thử nghiệm và đánh giá áp dụng các thực hành CSA trong các hệ thống NTTS ven biển. Bên cạnh đó, việc tham vấn ý kiến các cán bộ có kinh nghiệm và trình độ chuyên môn về các lĩnh vực khí tượng thủy văn, $\mathrm{BĐKH,} \mathrm{môi} \mathrm{trường,}$ thủy sản và các cán bộ hiện đang làm việc tại các ban ngành thuộc vùng duyên hải Bắc Bộ và Bắc Trung Bộ tiếp xúc trực tiếp với người dân, đồng thời nắm được thông tin trong các lĩnh vực mà mình quản lý trên địa bàn đóng vai trò trụ cột trong xây dựng thang điểm cho bộ tiêu chí.

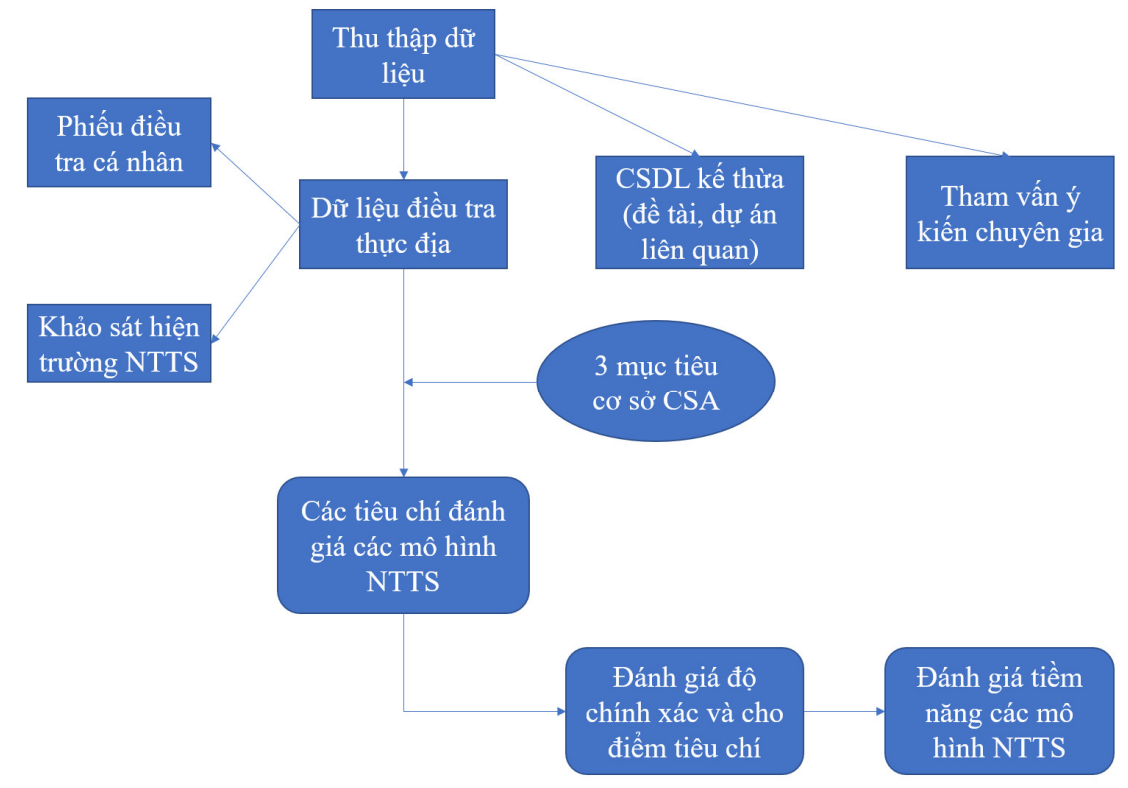

Hình 2. Phương pháp tiếp cận trong đề tài.

Sau khi thu thập được các thông tin về thực trạng và điều kiện môi trường NTTS, đề tài tiến hành chọn lọc các yếu tố nhằm đánh giá mô hình dựa trên 3 mục tiêu trụ cột của CSA. Các chỉ tiêu này, sau đó được đánh giá xếp hạng theo thang điểm từ 1 đến 5 tương ứng với mô hình không có tiềm năng phát triển đến có tiềm năng phát triển $(\geq 4)$.

\section{3. Đề xuất bộ tiêu chí đánh giá các mô hình NTTS thông minh thích ứng BĐKH}

Dựa trên cơ sở lý thuyết về NTTS ven biển thông minh với BĐKH (CSA) được trình bày ở trên, bộ tiêu chí được xây dựng hướng tới ba mục tiêu của CSA song song với các tiêu chí về điều kiện tự nhiên, kinh tế cũng như tính ổn định và phù hợp của môi trường nuôi. Trong đó, thứ 
nhất là tiêu chí về điều kiện tự nhiên, kinh tế xã hội, cơ sở vật chất để ứng dụng mô hình thủy sản ứng phó với BĐKH. Thứ hai là tiêu chí về năng suất, hiệu quả kinh tế, bền vững đối với hệ thống NTTS ven biển thông minh với BĐKH. Tiếp đó, tiêu chí về sự phù hợp và ổn định của môi trường nuôi trong hệ thống NTTS ven biển thông minh với BĐKH; Cuối cùng là 3 tiêu chí về khả năng phục hồi đối với hệ thống NTTS ven biển thông minh với $\mathrm{BĐKH,} \mathrm{về} \mathrm{an} \mathrm{ninh} \mathrm{lương}$ thực đối với hệ thống NTTS ven biển thông minh với BĐKH, về giảm phát thải khí nhà kính đối với hệ thống NTTS ven biển thông minh với BĐKH.

\subsection{Nhóm tiêu chí đảm bảo ANLT (mục tiêu 1)}

An ninh lương thực có thể hiểu là lúc nào cũng có đủ nguồn cung cấp lương thực, thực phẩm cơ bản của thế giới để đảm bảo việc tiêu dùng lương thực, thực phẩm ngày một nhiều hơn và để bù đắp được những biến động trong sản xuất và giá cả, theo đó, an ninh lương thực không chỉ là vấn đề sản xuất mà bao gồm cả vấn đề chất lượng thực phẩm, giá cả. ANLT ở các cấp độ cá nhân, hộ gia đình, khu vực và toàn cầu khi tất cả mọi người lúc nào cũng tiếp cận được về mặt vật lý và kinh tế đối với nguồn lương thực đầy đủ, an toàn và đảm bảo dinh dưỡng, để đáp ứng nhu cầu bữa ăn và sở thích đối với thức ăn, nhằm đảm bảo một cuộc sống năng động và khoẻ mạnh. Mặt khác, ANLT còn hiểu theo nghĩa rộng, nghĩa là an ninh lương thực của đất nước phải chuyển dịch từ khả năng chỉ có lúa gạo sang các vấn đề toàn diện hơn là an ninh và cân bằng dinh dưỡng, an toàn thực phẩm cũng như khả năng cung ứng các nguồn thức ăn cho chăn nuôi gia súc, gia cầm, thủy hải sản.

Theo định nghĩa như trên thì có nhóm tiêu chí để xét đến an ninh lương thực gồm có: (1) Mở rộng quy mô diện tích NTTS thâm canh; (2) Ứng dụng công nghệ cao nâng cao năng suất NTTS; (3) Lựa chọn giống thủy sản cho năng suất cao; (4) Giảm tổn thất do dịch bệnh, môi trường; (5) Thu nhập người NTTS tăng; (6) Chi phí sản xuất giảm; (7) Giá bán sản phẩm NTTS tốt, ổn định; (8) Hiệu quả kinh tế tăng; (9) Chất lượng sản phẩm NTTS đảm bảo; (10) Khả năng tiếp cận sản phẩm NTTS thuận lợi.

\subsection{Nhóm tiêu chí thích úng/phục hồi với BĐKH (mục tiêu 2)}

Khả năng hồi phục là khả năng của đối tượng (hệ thống NTTS ven biển) duy trì các chức năng sinh lý ở trạng thái thích ứng và phục hồi nhanh chóng sau thay đổi đột biến (shock and stress) và các tác động của BĐKH.

Khả năng thích ứng mặt khác là khả năng của đối tượng (hệ thống NTTS ven biển) trong việc hòa nhập, thích nghi nhanh chóng với sự thay đổi khi có sự trợ giúp của con người. Ví dụ chọn đối tượng nuôi có khả năng thích ứng tốt với sự thay đổi của các yếu tố môi trường (độ mặn, nhiệt độ,...), thì có khả năng thích ứng được với những tác động của $\mathrm{BĐKH.}$

Đối với lĩnh vực thủy sản, xây dựng mô hình thích ứng và phục hồi là thực hiện những việc để làm giảm mức độ bị tổn thương hoặc tránh không bị tổn thương do tác động của BĐKH đối với con người, các hệ thống sản xuất và hệ thống tự nhiên, hoặc để tận dụng cơ hội có lợi do BĐKH mang lại, hoặc để khắc phục các hậu quả của BĐKH, phục hồi sau khi bị ảnh hưởng bởi $\mathrm{BĐKH}$. Có thể thích ứng bằng các cách: (i) tránh các nguy cơ bị tác động của $\mathrm{B} Đ K H$, (ii) giảm mức độ bị tổn thương do BĐKH, và (iii) tăng khả năng thích nghi BĐKH.

Theo định nghĩa như trên thì có nhóm tiêu chí để xét thích ứng với với biến đổi khí hậu gồm có: (1) Sử dụng giống thủy sản có khả năng thích ứng với biến động môi trường (đối tượng nuôi rộng muối, rộng nhiệt,...) đồng thời lựa chọn địa điểm nuôi có điều kiện tự nhiên phù hợp với hệ thống NTTS ít chịu tác động của BĐKH; (2) Cải thiện hệ thống cơ sở hạ tầng vùng NTTS đồng thời đa dạng hóa hệ thống NTTS và đối tượng NTTS vùng ven biển; (3) Thay đổi mùa vụ NTTS 
phù hợp và cải tiến quy trình kỹ thuật, giúp các loài thủy sản mau lớn; (4) Sử dụng công nghệ cao (công nghệ tuần hoàn nước, NTTS trong nhà kính,..) hạn chế các tác động môi trường bên ngoài; (5) Nhận thức người NTTS về tác động của BĐKH; (6) Cải tiến, nâng cao hệ thống giám sát môi trường và dịch bệnh; (7) Hệ thống nuôi tiếp cận được với nơi an toán khi gặp thiên tai.

\subsection{Nhóm tiêu chí nhằm giảm phát thải KNK (mục tiêu 3)}

Khí Nhà Kính là những khí có khả năng hấp thụ các bức xạ sóng dài (hồng ngoại) được phản xạ từ bề mặt Trái Đất khi được chiếu sáng bằng ánh sáng mặt trời, sau đó phân tán nhiệt lại cho Trái Đất, gây nên hiệu ứng nhà kính. Có 06 loại khí nhà kinh theo quy định của Nghị định thư Kyoto là: Carbon dioxide $\left(\mathrm{CO}_{2}\right)$, Methane $\left(\mathrm{CH}_{4}\right)$ Nitrous oxide $\left(\mathrm{N}_{2} \mathrm{O}\right)$, Hydrofluorocarbons (HFCs), Perfluorocarbons ( $\mathrm{PFCs})$, Sulphur hexafluoride $\left(\mathrm{SF}_{6}\right)$. Đây là nguyên nhân chính dẫn tới $\mathrm{BĐKH}$ toàn cầu và gây ra các tác động tiêu cực đến môi trường cũng như hệ sinh thái hiện nay. Tuy nhiên, mỗi lĩnh vực kinh tế khác nhau có các phương án và hoạt động tương ứng giúp giảm phát thải KNK.

Các hoạt động, biện pháp giảm phát thải khí nhà kính trong lĩnh vực nông nghiệp bao gồm: (1) Ứng dụng các biện pháp canh tác lúa tiên tiến theo hướng tiết kiệm nước và giảm chi phí đầu vào; (2) Các biện pháp kỹ thuật nâng cao hiệu quả sử dụng phân đạm, giảm phát thải $\mathrm{N}_{2} \mathrm{O}$ trong canh tác lúa; (3) Các giải pháp tiết kiệm năng lượng, nhiên liệu trong làm đất, tưới nước cho các cây trồng công nghiệp; (4) Úng dụng các biện pháp canh tác tối thiểu nhằm giảm phát thải $\mathrm{KNK}$; (5) Thu gom, tái chế, tái sử dụng các phụ phẩm nông nghiệp; (6) Phát triển và ứng dụng công nghệ xử lý chất thải hữu cơ trong canh tác rau màu, mía, cây công nghiệp ngắn và dài ngày; (7) Thay đổi khẩu phần thức ăn trong chăn nuôi gia súc, gia cầm; (8) Cung cấp bánh dinh dưỡng MUB cho bò sữa; (9) Úng dụng quy trình Thực hành sản xuất nông nghiệp tốt ở Việt Nam (VIETGAP) trong chăn nuôi; (10) Sử dụng kháng sinh từ vi khuẩn, vi khuẩn đường một để giảm mức độ phát thải khí nhà kính từ chăn nuôi; (11) Phát triển công nghệ khí sinh học và hệ thống thu gom, lưu giữ, xử lý phân chuồng trong chăn nuôi gia súc, gia cầm.

Các hoạt động và phương án giảm phát thải KNK trong lĩnh vực sử dụng đất, thay đổi sử dụng đất, lâm nghiệp như: (1) Hoạt động tăng khả năng hấp thụ bằng cách bảo vệ rừng; (2) Trồng rừng, tái trồng rừng; (3) Đẩy mạnh phục hồi rừng, tái sinh tự nhiên; (4) Giảm phát thải khí nhà kính thông qua nỗ lực hạn chế mất rừng và suy thoái rừng, quản lý bền vững tài nguyên rừng, bảo tồn và nâng cao trữ lượng các-bon rừng (REDD+).

Các hoạt động và phương án giảm phát thải KNK trong lĩnh vực chất thải như: (1) Thu hồi và sử dụng khí mê-tan $\left(\mathrm{CH}_{4}\right)$ từ các bãi chôn lấp rác; (2) Xử lý nước thải công nghiệp.

Dựa trên các khái nhiệm và các biện pháp giảm phát thải $K N K$, nghiên cứu đưa ra nhóm tiêu chí về giảm phát thải KNK đối với hệ thống NTTS ven biển thông minh với BĐKH như sau: (1) Giảm phát thải KNK thông qua việc sử dụng hợp lý các nguyên liệu đầu vào; (2) Trong quá trình NTTS sử dụng các thiết bị tiết kiệm điện năng (máy bơm, máy quạt, sục khí, ...); (3) Cắt giảm việc sử dụng các nguồn năng lượng hóa thạch thay bằng các nguồn năng lượng tự nhiên (năng lượng mặt trời, năng lượng gió,...); (4) Ửng dụng kỹ thuật vào xử lý chất thải NTTS, sử dụng hệ thống Biogas để xử lý chất thải và thu hồi và sử dụng khí $\mathrm{CH}_{4} ;(5)$ Phát triển hệ thống nuôi sử dụng thức ăn tự nhiên, các đối tượng ăn lọc, công nghệ nuôi giảm hệ số thức ăn FCR (Feed Conversion Efficiency); (6) Phát triển môi hình NTTS kết hợp với với rừng ngập mặn $\mathrm{RNM}$ và trồng rong biển để tăng khả năng hấp thụ KNK; (7) Úng dụng VietGAP trong NTTS và sử dụng hệ thống sinh học trong thu gom và xử lý các chất thải NTTS.

Từ việc đánh giá chi tiết các yếu tố cấu thành và đảm bảo ba mục tiêu cơ sở của CSA, cùng với các tiêu chí được xây dựng trên việc đánh giá các điều kiện tự nhiên, kinh tế xã hội, cơ sở vật 
chất để ứng dụng mô hình thủy sản ứng phó với $\mathrm{BĐKH,} \mathrm{nghiên} \mathrm{cứu} \mathrm{tiến} \mathrm{hành} \mathrm{tổng} \mathrm{hợp} \mathrm{bộ} \mathrm{tiêu}$ chí như trong Bảng 1 .

Bảng 1. Tổng hợp bộ tiêu chí đánh giá các hệ thống NTTS ven biển thông minh thích ứng BĐKH cho vùng duyên hải Bắc Bộ và Bắc Trung Bộ.

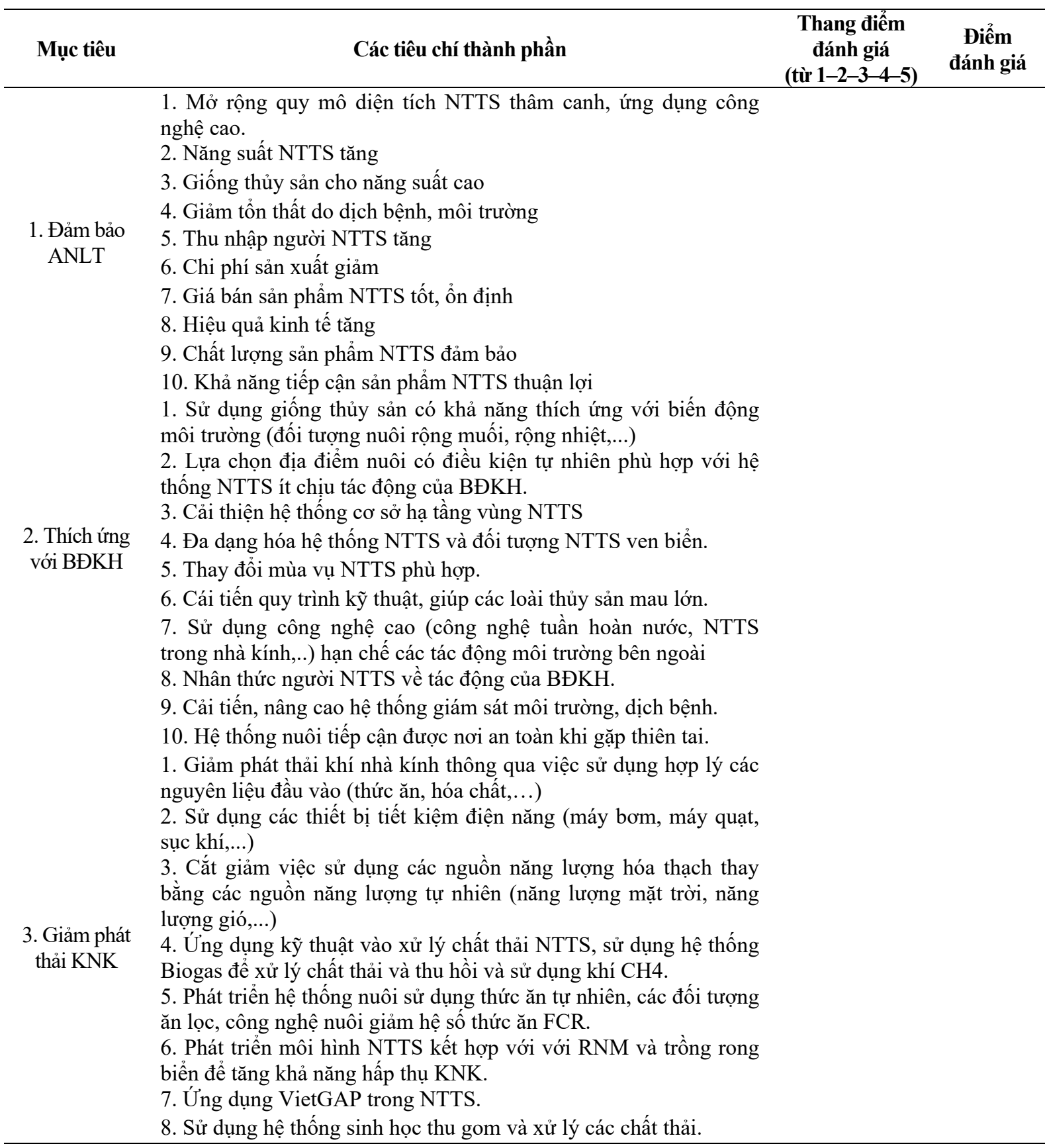

Ghi chú: Điểm đánh giá trung bình các tiêu chí; Có tiêu chí bị đánh giá điểm 1

Việc lượng hóa các chỉ tiêu trong bộ tiêu chí hệ thống NTTS ven biển thông minh với $\mathrm{BĐKH}$ được thực hiện theo hình thức quy đổi các giá trị theo thang điểm từ 1 đến 5 . Trong đó, các chỉ tiêu định danh được cho điểm dưới dạng Có/Không có với Có: Tương đương 5; Không có: Tương đương 1 . Các chỉ tiêu định tính ở dạng liên tục: Chia làm 5 mức (cho điểm từ 1-5): 
Mức thấp nhất: 1; Mức áp dưới trung bình: 2; Mức trung bình: 3; Mức áp trên trung bình: 4; Mức cao nhất: 5 . Với các chỉ tiêu có thể tính theo tỷ lệ, các chỉ tiêu được tính theo tỷ lệ \% và quy đổi từ tỷ lệ $\%$ ra hệ số từ 1 đến 5 như sau: Tỷ lệ $\leq 20 \%$ tương đương 1 , Tỷ lệ từ khoảng $>20 \%$ đến $\leq 40 \%$ tương đương 2 ; Tỷ lệ từ khoảng $>40 \%$ đến $\leq 60 \%$ tương đương 3 ; Tỷ lệ từ khoảng $>$ $60 \%$ đến $\leq 80 \%$ tương đương 4 ; Tỷ lệ từ khoảng $>80 \%$ đến $100 \%$ tương đương 5 .

\subsection{Cách sử dụng bộ tiêu chí trong đánh giá hệ thống NTTS ven biển thông minh với BĐKH}

Chuyên gia hay cán bộ địa phương quản lý, cán bộ kỹ thuật, cán bộ cộng đồng... đều có thể sử dụng bộ tiêu chí để đánh giá nếu được tập huấn để hiểu được cơ sở hình thành nên bộ tiêu chí và cách thức cho điểm, cách thức tính toán hoặc điều chỉnh một số tiêu chí khi cần cho phù hợp với điều kiện đặc thù của từng loại hình, khu vực nuôi cụ thể. Khi tiến hành đánh giá hệ thống NTTS ven biển thông minh với BĐKH, nên áp dụng phương pháp PRA theo đó một nhóm 1-2 người đánh giá thảo luận với một nhóm khoảng 5-10 người gồm cán bộ cộng đồng, cán bộ địa phương và số còn lại là người NTTS. Giá trị của một tiêu chí cụ thể là giá trị thống nhất trong nhóm sau khi đã được thảo luận kỹ.

Căn cứ vào tổng số điểm đánh để lựa chọn mô hình NTTS ven biển thông minh với BĐKH. Mô hình được chọn là mô hình NTTS có số điểm đánh giá trung bình của các tiêu chí $\geq 3$ và không có tiêu chí nào có điểm $=1$. Dựa trên tổng số điểm đánh giá các tiêu chí để phân loại các mô hình NTTS ven biển thông minh với BĐKH theo các mức như sau:

+ Tổng điểm trung bình các tiêu chí: $>4$ và không có tiêu chí nào có điểm bằng 1 là mô hình NTTS ven biển thông minh với $\mathrm{BĐKH}$ rất có tiềm năng phát triển (được ưu tiên lựa chọn và nhận rộng).

+ Tổng điểm trung bình các tiêu chí nằm trong khoảng: $\geq 3$ đến $\leq 4$ và không có tiêu chí nào có điểm bằng 1 là mô hình NTTS ven biển thông minh với $\mathrm{BĐKH} \mathrm{có} \mathrm{tiềm} \mathrm{năng} \mathrm{phát} \mathrm{triển} \mathrm{(được}$ lựa chọn và nhận rộng).

+ Tổng điểm trung bình các tiêu chí nằm trong khoản: $>2$ đến $<3$ và không có tiêu chí nào có điểm bằng 1 là mô hình NTTS ven biển thông minh với BĐKH ít tiềm năng phát triển (Không nên lựa chọn và không nhân rộng).

+ Tổng điểm trung bình các tiêu chí $\leq 2$ hoặc có tiêu chí có điểm bằng 1 là mô hình NTTS ven biển thông minh với BĐKH không có tiềm năng phát triển (Tuyệt đối không được lựa chọn và không nhân rộng).

Nội dung bộ tiêu chí đánh giá các hệ thống NTTS ven biển thông minh với BĐKH cho vùng duyên hải Bắc Bộ và Bắc Trung Bộ đã bao quát hầu hết các khía cạnh về hệ thống NTTS ven biển thông minh với $\mathrm{BĐKH}$; tiêu chí đánh giá cụ thể ở cả 03 mục tiêu CSA: (i) Đảm bảo được an ninh lương thực; (ii) Thích ứng với $\mathrm{BĐKH}$; (iii) Giảm phát phát thải KNK. Các bộ tiêu chí này cần được áp dụng tùy theo vùng nuôi, đối tượng nuôi và điều kiện nuôi để thay đổi và cho điểm. Uu điểm của các tiêu chí áp dụng cho việc đảm bảo ANLT là đảm bảo năng suất và hiệu quả kinh tế cho mô hình áp dụng trong khi bộ tiêu chí thích ứng BĐKH giúp đối tượng nuôi được đa dạng hóa, hiệu quả đối với sự thay đổi của các điều kiện thời tiết và môi trường và bộ tiêu chí giảm phát thải KNK giúp tăng cường sử dụng nguồn thức ăn tự nhiên, giảm chi phí. Tuy nhiên, để đảm bảo các tiêu chí giảm phát thải KNK và $A N L T$, các chi phí cho việc mở rộng vùng nuôi và áp dụng các phương pháp kỹ thuật xử lý chất thải tiến bộ còn cao. Bên cạnh đó, phần lớn các tiêu chí trên còn chủ yếu dựa vào đánh giá chủ quan để phân cấp và thay đổi theo vùng, đối tượng, điều kiện áp dụng mô hình vì vậy kết quả còn cần có sự đánh giá cụ thể của chuyên gia cũng và phụ thuộc vào điều kiện kinh tế-xã hội của vùng áp dụng. 


\section{Kết quả áp dụng thí điểm bộ tiêu chí đánh giá hệ thống NTTS thông minh với BĐKH}

Nghiên cứu đã tiến hành áp dụng bộ tiêu chí đề xuất để đánh giá cho một số mô hình NTTS hiện đang triển khai tại các tỉnh ven biển Bắc Bộ và Bắc Trung Bộ. Kết quả tính toán các tiêu chí chi tiết bước đầu được thực hiện thí điểm cho hai mô hình nuôi ngao bãi triều-đề xuất và mô hình nuôi ngao công nghiệp tỉnh Thái Bình được trình bày trong Bảng 2.

Bảng 2. Điểm đánh giá các tiêu chí thành phần cho tỉnh Thái Bình.

\begin{tabular}{|c|c|c|c|c|c|}
\hline \multirow[b]{2}{*}{ Mục tiêu } & \multirow[b]{2}{*}{ Các tiêu chí thành phần } & \multicolumn{2}{|c|}{$\begin{array}{l}\text { Mô hình nuôi ngao } \\
\text { bãi triều - đề xuất }\end{array}$} & \multicolumn{2}{|c|}{$\begin{array}{l}\text { Mô hình nuôi ngao } \\
\text { công nghiệp }\end{array}$} \\
\hline & & $\begin{array}{l}\text { Thang } \\
\text { điểm đánh } \\
\text { giá }\end{array}$ & $\begin{array}{l}\text { Điểm } \\
\text { đánh giá } \\
\text { quy đổi }\end{array}$ & $\begin{array}{l}\text { Thang } \\
\text { điểm } \\
\text { đánh giá }\end{array}$ & $\begin{array}{l}\text { Điểm } \\
\text { đánh giá } \\
\text { quy đổi }\end{array}$ \\
\hline \multirow{9}{*}{$\begin{array}{l}\text { 1. Đảm bảo } \\
\text { ANLT }\end{array}$} & $\begin{array}{l}\text { 1. Mở rộng quy mô diện tích NTTS thâm } \\
\text { canh, ứng dụng công nghệ cao. }\end{array}$ & $60-80 \%$ & 4 & $20-40 \%$ & 2 \\
\hline & $\begin{array}{l}\text { 2. Úng dụng công nghệ cao nâng cao năng } \\
\text { suất NTTS tăng }\end{array}$ & cao nhất & 5 & trên TB & 4 \\
\hline & 3. Lựa chọn giống thủy sản cho năng suất cao & cao nhất & 5 & cao nhất & 5 \\
\hline & 4. Giảm tổn thất do dịch bệnh, môi trường & $60-80 \%$ & 4 & $60-80 \%$ & 4 \\
\hline & 5. Giá bán sản phẩm NTTS tốt, ổn định & cao nhất & 5 & Trên TB & 4 \\
\hline & 6. Chất lượng sản phẩm NTTS đảm bảo & cao nhất & 5 & $\mathrm{~Tb}$ & 3 \\
\hline & $\begin{array}{l}\text { 10. Khả năng tiếp cấp sản phẩm NTTS thuận } \\
\text { lợi }\end{array}$ & cao nhất & 5 & cao nhất & 5 \\
\hline & $\begin{array}{l}\text { 1. Sử dụng giống thủy sản có khả năng thích } \\
\text { ứng với biến động môi trường (đối tượng nuôi } \\
\text { rộng muối, rộng nhiệt,...) }\end{array}$ & trên TB & 4 & cao nhất & 5 \\
\hline & $\begin{array}{l}\text { 2. Lựa chọn địa điểm nuôi có điều kiện tự } \\
\text { nhiên phù hợp với hệ thống NTTS ít chịu tác } \\
\text { động của BĐKH. }\end{array}$ & trên TB & 4 & trên TB & 4 \\
\hline \multirow{7}{*}{$\begin{array}{l}\text { 2. Thích ứng } \\
\text { với BĐKH }\end{array}$} & 3. Cải thiện cơ sở hạ tầng vùng NTTS & trên TB & 4 & cao nhất & 5 \\
\hline & $\begin{array}{l}\text { 4. Đa dạng hóa hệ thống NTTS và đối tượng } \\
\text { NTTS vùng ven biển. }\end{array}$ & $60-80 \%$ & 4 & $40-60 \%$ & 3 \\
\hline & 5. Thay đổi mùa vụ NTTS phù hợp. & cao nhất & 5 & Trên TB & 4 \\
\hline & $\begin{array}{l}\text { 6. Cái tiến quy trình kỹ thuật, giúp các loài } \\
\text { thủy sản mau lớn. }\end{array}$ & cao nhất & 5 & cao nhất & 5 \\
\hline & $\begin{array}{l}\text { 7. Sử dụng công nghệ cao (công nghệ tuần } \\
\text { hoàn nước, NTTS trong nhà kính,..) hạn chế } \\
\text { các tác động môi trường bên ngoài }\end{array}$ & trên TB & 4 & cao nhất & 5 \\
\hline & $\begin{array}{l}\text { 8. Cải tiến, nâng cao hệ thống giám sát môi } \\
\text { trường và dịch bệnh. }\end{array}$ & $40-60 \%$ & 3 & $40-60 \%$ & 3 \\
\hline & $\begin{array}{l}\text { 9. Hệ thống nuôi tiếp cận được với nơi an toàn } \\
\text { khi gặp thiên tai. }\end{array}$ & $40-60 \%$ & 3 & $40-60 \%$ & 3 \\
\hline \multirow{4}{*}{$\begin{array}{l}\text { 3. Giảm phát } \\
\text { thải KNK }\end{array}$} & $\begin{array}{l}\text { 1. Sử dụng các thiết bị tiết kiệm điện năng } \\
\text { (máy bơm, máy quạt, sục khí,...) }\end{array}$ & trên TB & 4 & Có & 5 \\
\hline & $\begin{array}{l}\text { 2. Cắt giảm việc sử dụng các nguồn năng } \\
\text { lượng hóa thạch thay bằng các nguồn năng } \\
\text { lượng tự nhiên (năng lượng mặt trời, năng } \\
\text { lượng gió,...) }\end{array}$ & cao nhất & 5 & trên TB & 4 \\
\hline & $\begin{array}{l}\text { 3. Úng dụng kỹ thuật vào xử lý chất thải } \\
\text { NTTS, sử dụng hệ thông Biogas để xử lý chất } \\
\text { thải và thu hồi và sử dụng khí } \mathrm{CH} 4 \text {. }\end{array}$ & cao nhất & 5 & cao nhất & 5 \\
\hline & 4. Phát triển môi hình NTTS kết hợp với với & trên TB & 4 & dưới tb & 2 \\
\hline
\end{tabular}




\begin{tabular}{|c|c|c|c|c|c|}
\hline \multirow{5}{*}{ Mục tiêu } & \multirow[b]{2}{*}{ Các tiêu chí thành phần } & \multicolumn{2}{|c|}{$\begin{array}{l}\text { Mô hình nuôi ngao } \\
\text { bãi triều - đề xuất }\end{array}$} & \multicolumn{2}{|c|}{$\begin{array}{l}\text { Mô hình nuôi ngao } \\
\text { công nghiệp }\end{array}$} \\
\hline & & $\begin{array}{c}\text { Thang } \\
\text { điểm đánh } \\
\text { giá }\end{array}$ & $\begin{array}{c}\text { Điểm } \\
\text { đánh giá } \\
\text { quy đồi }\end{array}$ & $\begin{array}{c}\text { Thang } \\
\text { điểm } \\
\text { đánh giá }\end{array}$ & $\begin{array}{c}\text { Điểm } \\
\text { đánh giá } \\
\text { quy đồi }\end{array}$ \\
\hline & $\begin{array}{l}\text { RNM và trồng rong biển để tăng khả năng hấp } \\
\text { thụ KNK. }\end{array}$ & & & & \\
\hline & 5. Úng dụng VietGAP trong NTTS. & cao nhất & 5 & cao nhất & 5 \\
\hline & $\begin{array}{l}\text { 6. Sự dụng hệ thống sinh học trong thu gom và } \\
\text { xử lý các chât thải NTTS. }\end{array}$ & trên TB & 4 & Có & 5 \\
\hline \multirow{2}{*}{\multicolumn{2}{|c|}{$\begin{array}{l}\text { - Điểm đánh giá trung bình các tiêu chí } \\
\text { - Có tiêu chí bị đánh giá điểm } 1\end{array}$}} & & 4,46 & & 3,82 \\
\hline & & & Có & & Không \\
\hline
\end{tabular}

Kết quả cho thấy mô hình nuôi ngao bãi triều đề xuất phù hợp và có tiềm năng phát triển hơn ở tỉnh Thái Bình với điểm đánh giá trung bình cho bộ tiêu chí tổng hợp thu được khá cao, đạt 4.46. Trong đó các tiêu chí đảm bảo ANLT đều đảm bảo cao nhất và quy mô mở rộng diện tích cũng như khả năng ứng dụng công nghệ cao đều đạt từ $60 \%-80 \%$. Trên cơ sở đảm bảo tính thích ứng với $\mathrm{BĐKH}$, mặc dù hầu hết các tiêu trí đều đạt mức trên trung bình thì các tiêu chí về khả năng thay đổi mùa vụ và khả năng cải tiến quy trình cũng như kỹ thuật của mô hình này tại Thái Bình cũng cho thấy tiềm năng cao nhất. Bên cạnh đó, đối với việc áp dụng các công nghệ, ứng dụng cao nhằm giảm thiểu phát thải $\mathrm{KNK}$ cũng có tiềm năng cao khi đánh giá tất cả các tiêu chí thành phần cho Thái Bình. Các tính toán tiêu chí thành phần cũng được thực hiện tương tự cho các tỉnh thành còn lại tại Bắc Bộ và Bắc Trung Bộ. Kết quả đánh giá tổng hợp bộ tiêu chí cho các tỉnh như ở Bảng 3.

Trên cơ sở đánh giá thông qua bộ tiêu chí đề xuất, cho thấy một số các mô hình NTTS được đánh giá là thông minh thích ứng với $\mathrm{BĐKH} \mathrm{như} \mathrm{sau:}$

+ Mô hình NTTS trong rừng ngập mặn: cung cấp sinh kế ổn định hơn, ít rủi ro hơn và thích ứng với khí hậu, đặc biệt cho những hộ nghèo, không có lựa chọn thay thế đồng thời cung cấp một vùng đệm ven biển chống lại gió bão và nước biển dâng cao.

+ Mô hình nuôi xen ghép kêt hợp: từ hai đối tượng trở lên trên cùng 1 diện tích ao nuôi nhằm tận dụng diện tích ao nuôi. Mô hình này vừa tận dụng được nguồn dinh dưỡng và thức ăn thừa giữa các đối tượng, giảm chi phí sản xuất vừa tăng năng suất và đa dạng hóa sản phẩm trên cùng diện tích nuôi.

+ Mô hình nuôi nhuyễn thể bãi triều và trong ao đầm nước lợ: giúp cải thiện chất lượng nước bằng cách lọc bùn cát và chất dinh dưỡng thừa, không tiêu thụ thức ăn công nghiệp.

+ Mô hình nuôi cá biển lồng bè là mô hình nuôi hở trong eo vịnh kín. Uuu điểm là tận dụng mặt nước biển còn nhiều, không chiếm đất nông nghiệp, năng suất, sản lượng cao, hiệu quả kinh tế cao, giải quyết vấn đề nguồn lợi cá biển ngày càng giảm. Tuy nhiên lại phụ thuộc nhiều vào khí hậu thời tiết và biến động của môi trường do đó hiệu quả kinh tế không ổn định.

Bảng 3. Kết quả đánh giá một số mô hình NTTS theo bộ tiêu chí đề xuất.

\begin{tabular}{ccccc}
\hline $\begin{array}{c}\text { Địa } \\
\text { phương }\end{array}$ & \multicolumn{1}{c}{ Mô hình NTTS đánh giá } & $\begin{array}{c}\text { Điểm đánh giá } \\
\text { trung bình }\end{array}$ & $\begin{array}{c}\text { Có tiêu chí } \\
\text { đánh giá =1 }\end{array}$ & Ghi chú \\
\hline Thái Bình & Mô hình nuôi ngao bãi triều đề xuất & 4,46 & không & $\begin{array}{l}\text { Mô hình rất có tiềm } \\
\text { năng phát triển } \\
\text { Mô hình không có tiềm } \\
\text { năng phát triền } \\
\text { Mồ hình không có tiềm } \\
\text { năng phát triển }\end{array}$ \\
\hline
\end{tabular}




\begin{tabular}{|c|c|c|c|c|}
\hline $\begin{array}{c}\text { Địa } \\
\text { phương }\end{array}$ & Mô hình NTTS đánh giá & $\begin{array}{l}\text { Điểm đánh giá } \\
\text { trung bình }\end{array}$ & $\begin{array}{l}\text { Có tiêu chí } \\
\text { đánh giá }=1\end{array}$ & Ghi chú \\
\hline \multirow[b]{2}{*}{ Nam Định } & $\begin{array}{l}\text { Mô hình nuôi kết hợp trong rừng } \\
\text { ngâp mặn đề xuât }\end{array}$ & 4,29 & không & $\begin{array}{l}\text { Mô hình rất có tiềm } \\
\text { năng phát triển }\end{array}$ \\
\hline & $\begin{array}{l}\text { Mô hình nuôi } 1 \text { đối tượng } \\
\text { (cua/tôm...) trong rừng ngập mận }\end{array}$ & 3,96 & không & $\begin{array}{l}\text { Mô hình có tiềm năng } \\
\text { phát triển }\end{array}$ \\
\hline \multirow{3}{*}{$\begin{array}{l}\text { Quảng } \\
\text { Ninh }\end{array}$} & $\begin{array}{l}\text { Mô hình nuôi cá lồng bè vịnh kín } \\
\text { ven biển đề xuất }\end{array}$ & 4,25 & không & $\begin{array}{l}\text { Mô hình rất có tiềm } \\
\text { năng phát triển }\end{array}$ \\
\hline & $\begin{array}{l}\text { Mô hình nuôi quảng canh truyền } \\
\text { thống }\end{array}$ & 2,64 & Có & $\begin{array}{l}\text { Mô hình không có tiềm } \\
\text { năng phát triển }\end{array}$ \\
\hline & $\begin{array}{l}\text { Mô hình nuôi công nghiệp, nuôi } \\
\text { thâm canh }\end{array}$ & 3,54 & Có & $\begin{array}{l}\text { Mô hình không có tiềm } \\
\text { năng phát triện }\end{array}$ \\
\hline \multirow{3}{*}{ T.T. Huế } & $\begin{array}{l}\text { Mô hình hệ thống nuôi kết hợp } \\
\text { trong ao đầm nước lợ đề xuất }\end{array}$ & 4,36 & không & $\begin{array}{l}\text { Mô hình rất có tiềm } \\
\text { năng phát triển }\end{array}$ \\
\hline & $\begin{array}{l}\text { Mô hình nuôi trồng thủy sản trong } \\
\text { ao đầm nước lợ nuôi ghép nhiều đối } \\
\text { tượng đang triển khai ở đại phương }\end{array}$ & 4,07 & không & $\begin{array}{l}\text { Mô hình có tiềm năng } \\
\text { phát triền }\end{array}$ \\
\hline & $\begin{array}{l}\text { Mô hình nuôi thủy sản trong ao } \\
\text { đầm nước lợ nuôi } 1 \text { đối tượng } \\
\text { truyền thống }\end{array}$ & 2,71 & Có & $\begin{array}{l}\text { Mô hình không có tiềm } \\
\text { năng phát triền }\end{array}$ \\
\hline
\end{tabular}

\section{Kết luận}

Bộ tiêu chí đánh giá các hệ thống NTTS ven biển thông minh với BĐKH cho vùng duyên hải Bắc Bộ và Bắc Trung Bộ đã bao quát hầu hết các khía cạnh về hệ thống NTTS ven biển thông minh với $\mathrm{BĐKH}$; tiêu chí đánh giá cụ thể ở cả 03 mục tiêu CSA: (i) Đảm bảo được an ninh lương thực; (ii) Thích ứng với BĐKH; (iii) Giảm phát phát thải KNK. Trong mỗi tiêu chí chính có các nhóm tiêu chí phụ; các tiêu chí phụ đã được cụ thể hóa làm cơ sở cho việc đánh giá.

Kết quả sơ bộ tính toán cho các tỉnh thành ở Bắc Bộ-Bắc Trung Bộ cho thấy các mô hình nuôi quảng canh, thâm canh truyền thống tại Quảng Ninh, hay mô hình nuôi ngao bãi triều truyền thống tại Thái Bình và mô hình NTTS trong ao đầm nước lợ truyền thống 1 đối tượng đều không cho thấy tiềm năng phát triển. Ngược lại, việc áp dụng các mô hình cải tiến thích ứng BĐKH cho kết quả khả quan với tiềm năng phát triển cao cho tất cả các tỉnh thành. Tùy theo hình thức và công nghệ nuôi, đối tượng nuôi và điều kiện của vùng nuôi có thể chứng minh việc không áp dụng một tiêu chí phụ nào đó. Việc không áp dụng chỉ được chấp nhận khi chuyên gia đánh giá xem xét thực tiễn.

Đóng góp của tác giả: Xây dựng ý tưởng nghiên cứu: H.N.K., T.Q.T.; Lựa chọn phương pháp nghiên cứu: T.V.T., T.Q.T.; Xử lý số liệu: T.V.T.; Viết bản thảo bài báo: T.Q.T; Chỉnh sửa bài báo: H.N.K.

Lời cảm ơn: Nghiên cứu này được thực hiện trong khuôn khổ nghiên cứu của đề tài "Nghiên cứu giải pháp phát triển nuôi trồng thuỷ sản ven biển thông minh thích ứng với biến đổi khí hậu vùng duyên hải Bắc Bộ và Bắc Trung Bộ", mã số BĐKH.18/16-20, thuộc Chương trình Khoa học và Công nghệ ứng phó với Biến đổi khí hậu, Quản lý tài nguyên và môi trường giai đoạn 2016-2020.

\section{Tài liệu tham khảo}

1. Climate smart agriculture sourcebook, Food and Agriculture Organization of the United Nations, 2013. 
2. Climate change adaptation in fisheries and aquaculture: compilation of initial examples, FAO Fisheries and Aquaculture, 2014.

3. Smit, B.; Pilifosova, O. Adaptation to Climate Change in the Context of Sustainable Development and Equity in Climate Change 2001: Impacts, Adaptation, and Vulnerability - Contribution of Working Group II to the Third Assessment Report of the Intergovernmental Panel on Climate Change; McCarthy, J.J., Canziani, O.F., Leary, N.A.,Dokken, D.J., White, K.S., Eds.; Cambridge University Press: Cambridge, UK, 2001; pp. 877-912.

4. Mendelsohn, R.; Dinar, A. Climate Change and Agriculture an Economic Analysis of Global Impacts, Adaptation and Distributional Effects. Edward Elgar Publishing, UKUSA, 2009 , p. 1.

5. Suraje, D.; Jeroen van der, S. Uncertainty and Climate Change Adaptation A Scoping Study. Utrecht, Netherlands: Copernicus Institute for Sustainable Development and Innovation, 2007.

6. Mendelsohn, R. Efficient Adaptation to Climate Change. Clim. Change 2000, 45, 583600. https://doi.org/10.1023/A:1005507810350.

7. CC-Dolloff, A.M.; Loboguerrero, M.; Lizarrazo, A.; Nowak, F.; Howland, N.; Andrieu, A.; Jarrvis. Decision-support framework for targeting investment towards climate-smart agriculture practices and programs, Our Common Future Under Climate Change Paris, 2015.

8. Onada, O.A.; Ogunola, O.S. Climate Smart Aquaculture: A Sustainable Approach to Increasing Fish Production in the Face of Climate Change in Nigeria. Int. J. Aquac. Fish Sci. 2016, $\quad 3, \quad 444-448$. http://www.fisheriesjournal.com/archives/2016/vol4issue3/PartF/4-2-110.pdf.

\title{
Development of the set of criteria to evaluate the Climate Smart Aquaculture system in the Northern-North Central Coast Vietnam
}

\author{
Hoang Ngoc Khac ${ }^{1,2 *}$, Trinh Quang Tu ${ }^{3}$, Tran Van Tam ${ }^{3}$ \\ 1 Global Change and Sustainable Development Research Institute; hnkhac@hunre.edu.vn; \\ ${ }^{2}$ Hanoi University of Natural Resources and Environment; \\ 3 Vietnam Institute of Fisheries Economics and Planning; tiquatuwagen@gmail.com; \\ hanhtam.vifep@gmail.com.
}

\begin{abstract}
Climate-smart fisheries and aquaculture as a part of Climate-smart Agriculture (CSA) have become an advanced approach in coping and adapting to climate change for aquaculture. These climate-smart aquaculture models are being introduced and implemented in the North-North Central area of Vietnam. However, to apply and set up these models effectively, it is necessary to develop a set of criteria of evaluation based on three main objectives of CSA. The research has developed sets of criteria to achieve sustainable food systems, climate change adaptation, greenhouse gas emissions reduction, and criteria to maintain productivity and model stabilization. These criteria have been calculated and evaluated for each province in the research areas. The results show that set of criteria plays a considerable role in evaluating and improve CSA models in the Northern-North Central Coast Vietnam and other coastal areas in Vietnam.
\end{abstract}

Keywords: Climate-smart aquaculture; Criteria; Greenhouse gas; Sustainable food system. 